\title{
Multifractal analysis of rainfall in coastal area in Pernambuco, Brazil
}

\author{
Análise multiffractal da precipitação na área costeira de Pernambuco, Brasil \\ Análisis multifractal de precipitación en la zona costera de Pernambuco, Brasil
}

Received: 01/27/2021 | Reviewed: 02/01/2021 | Accept: 02/02/2021 | Published: 02/08/2021

\author{
Ikaro Daniel de Carvalho Barreto \\ ORCID: https://orcid.org/0000-0001-7253-806X \\ Federal Rural University of Pernambuco, Brazil \\ E-mail: daniel.carvalho.ib@gmail.com \\ Tatijana Stosic \\ ORCID: https://orcid.org/0000-0002-5691-945X \\ Federal Rural University of Pernambuco, Brazil \\ E-mail: tastosic@gmail.com
}

\begin{abstract}
Global warming and climate change are the mayor concerns of scientists, engineers and policy makers because they affect every aspect of nature and human life. Rainfall and air temperature are the most important variables used to detect climate change, through the statistical analysis of set of indices that describe temperature and rainfall extremes. Over the last decades concepts and methods from complex system science were applied in analysis of hydrological data to describe variability of hydrological processes on multiple temporal and spatial scales. In this work we analyzed daily rainfall temporal series in Recife, Brazil (during the period from 1962 to 2019) using Multifractal Detrended Fluctuation analysis (MFDFA) in order to study long term correlations in subsets of small and large rainfall fluctuations. We calculated multifractal parameters (that quantify position of maximum, width and asymmetry of multifractal spectrum) which are related to different properties of rainfall fluctuations. By comparing the values of these parameters for two subperiods of 29 years, we found that after 1990, rainfall dynamics changed towards stronger persistency, weaker multifractality and decreased dominance of small fluctuations.
\end{abstract}

Keywords: Rainfall; Climate change; Multifractal.

\section{Resumo}

$\mathrm{O}$ aquecimento global e as mudanças climáticas são as principais preocupações dos cientistas, engenheiros e legisladores, porque afetam todos os aspectos da natureza e da vida humana. A precipitação e a temperatura do ar são as variáveis mais importantes para detectar as alterações climáticas, através da análise estatística de um conjunto de índices que descrevem os extremos de temperatura e precipitação. Nas últimas décadas, conceitos e métodos da ciência de sistemas complexos foram aplicados na análise de dados hidrológicos para descrever a variabilidade dos processos hidrológicos em múltiplas escalas temporais e espaciais. Neste trabalho, analisamos séries temporais de precipitação diária em Recife, Brasil (durante o período de 1962 a 2019) usando a análise Multifractal Detrended Fluctuation Analysis (MFDFA) a fim de estudar correlações de longo prazo em subconjuntos de pequenas e grandes flutuações de chuva. Calculamos parâmetros multifractais (que quantificam a posição de máximo, largura e assimetria do espectro multifractal) que estão relacionados a diferentes propriedades das flutuações da precipitação. Ao comparar os valores desses parâmetros para dois subperíodos de 29 anos, descobrimos que, após 1990, a dinâmica da chuva mudou para uma persistência mais forte, multifractalidade mais fraca e diminuição da dominância de pequenas flutuações.

Palavras-chave: Precipitação; Mudança climática; Multifractal.

\section{Resumen}

El calentamiento global y el cambio climático son las principales preocupaciones de los científicos, ingenieros y políticos porque afectan todos los aspectos de la naturaleza y la vida humana. Las precipitaciones y la temperatura del aire son las variables más importantes que se utilizan para detectar el cambio climático, mediante el análisis estadístico de un conjunto de índices que describen los extremos de temperatura y precipitación. Durante las últimas décadas, se aplicaron conceptos y métodos de la ciencia de sistemas complejos en el análisis de datos hidrológicos para describir la variabilidad de los procesos hidrológicos en múltiples escalas temporales y espaciales. En este trabajo analizamos series temporales de lluvia diaria en Recife, Brasil (durante el período de 1962 a 2019) utilizando el Multifractal Detrended Fluctuation Analysis (MFDFA) para estudiar las correlaciones a largo plazo en subconjuntos de fluctuaciones de lluvia pequeñas y grandes. Calculamos parámetros multifractales (que cuantifican la posición de máximo, ancho y asimetría del espectro multifractal) que se relacionan con diferentes propiedades de las fluctuaciones de las precipitaciones. Al comparar los valores de estos parámetros para dos subperíodos de 29 años, encontramos que después de 1990, la 
dinámica de la lluvia cambió hacia una persistencia más fuerte, una multifractalidad más débil y una dominancia disminuida de pequeñas fluctuaciones.

Palabras clave: Precipitación; Cambio climático; Multifractal.

\section{Introduction}

Rainfall is the primary input of hydrological cycle and its temporal and spatial variability affects other hydrological components as surface runoff, groundwater flow, interception, evaporation and soil moisture. Rainfall variability occurs at wide range of temporal and spatial scales which (directly or indirectly) can impact electricity production, agriculture, ecosystems, and human health (Arvor et al., 2014; Haines et al., 2006; Kabo-Bah et al., 2016; Weltzin et al., 2003).

While classical statistical methods remain the main tool in rainfall studies, by providing valuable information about rainfall regime as probability distribution, extreme values and trends, over the last decades considerable scientific effort was made to use methods from complex system science in order to access properties that emerge from nonlinearity and complexity of rainfall dynamics (Herr \& Krzysztofowicz, 2005; J. Park et al., 2011; Sa'adi et al., 2019).

These methods are based on concept of fractals and multifractals, chaos theory, information theory and complex networks (Douglas \& Barros, 2003a; Fuwape et al., 2017; Jha \& Sivakumar, 2017a; Xavier et al., 2019). It is well known that hydrological time series exhibit long term correlations at multiple temporal scales which is characteristic of multifractal processes (Douglas \& Barros, 2003a; Tan \& Gan, 2017). Multifractal methods were extensively used in analysis of rainfall data, the reported results include empirical studies, delineation of homogeneous rainfall areas, extreme values and validation of rainfall models (Adarsh et al., 2020; Douglas \& Barros, 2003b; A. P. García-Marín et al., 2015; Amanda P. García-Marín et al., 2008; Langousis et al., 2009; Svensson et al., 1996).

Recently Krzyszczak et al. 2019, analyzed meteorological data, including rainfall, from four locations (two in Poland and two in Bulgaria that are located in varying climatic zones) and showed that multifractal analysis is sensitive to the observed climate shifts: the changes in parameters that describe the shape of singularity spectrum indicate which properties of the underlying stochastic process were changed due to climate shift.

The objective of our work is to investigate if the preliminary results presented in that indicate that singularity spectra were susceptible to climatic shift, stand for different climate condition, in this case tropical sub humid which is present in coastal area of Pernambuco, Brazil (Krzyszczak et al., 2019).

\section{Methodology}

In this work we use the methodology Multifractal Detrended Fluctuation Analysis, which was developed to quantify multifractal correlations in nonstationary temporal series (Movahed et al., 2006). The data used in this work are daily rainfall temporal series recorded from 1962 to 2019 in Recife (Latitude: -8,06; Longitude: -34.96) provided by National Institute of Meteorology (Instituto Nacional de Meteorologia - INMET), obtained from site Recife (CURADO) 82900 with 11,3 m of altitude.

\subsection{Detrended Fluctuation Analysis (DFA)}

Detrended Fluctuation Analysis (DFA) is based on root-mean-square analysis of a random walk. It was introduced by Peng et al. (1994) to detect long-term correlations in non-stationary time series.

The DFA method can be summarized in 5 steps (Peng et al., 1994):

i) The original time series $x(i), i=1,2, \ldots, N$ is integrated, 


$$
y(k)=\sum_{i=1}^{k} x(i)-\langle x\rangle, k=1, \ldots, N
$$

where, $\langle x\rangle$ is the mean value of the series $x(i)$.

ii) The integrated series $y(k)$ is divided into $N_{n}=\operatorname{int}[N / n]$ non-overlapping windows of length $n$ and each window $w=$ $1, \ldots, N_{n}$ the local trend $y_{n, w}(k)$ is calculated using linear or polynomial fit.

iii)

In each window the local variance is determined as

$$
F^{2}(n, w)=\frac{1}{n} \sum_{i=(w-1) n+1}^{w n}\left[y(k)-y_{n, w}(k)\right]^{2}
$$

iv)

The detrended variance at scale $\mathrm{n}$ is then calculated as

$$
F^{2}(n)=\frac{1}{N_{n}} \sum_{w=1}^{N_{n}} F^{2}(n, w)
$$

This calculation (i-iv) is repeated for different window sizes which provides the relationship between the fluctuation function $F(n)$ and window size $n$. If long-term correlations are present in the original series, $F(n)$ increases with $n$ according to a power law:

$$
F(n) \sim n^{\alpha}
$$

The scaling exponent $\alpha$ (also called DFA exponent) can be obtained as the slope of the linear regression of $\log F(n)$ versus $\log n$ and for $0<\alpha<1$ is equal to Hurst exponent $\mathrm{H}$ which describes correlations in original series: the value $\alpha=0.5$ indicates the absence of correlations (white noise), $\alpha>0.5$ indicates persistent long-term correlations meaning that large (small) values are more likely to be followed by large (small) values, $\alpha<0.5$ indicates anti-persistent long-term correlations, meaning that large values are more likely to be followed by small values and vice versa. The value $1<\alpha<2$ indicates fractional Brownian motion with increments described by Hurst exponent $\mathrm{H}=\alpha-1$ (J. S. Park et al., 2011; Peng et al., 1994).

\subsection{Multifractal Detrended Fluctuation Analysis (MF-DFA)}

Multifractal detrended fluctuation analysis (MFDFA) was introduced by Kantelhardt et al. (2002) and has been widely used to analyze data in physiology, geophysics, ecology, climatology and finances (da Silva et al., 2020; De Benicio et al., 2013; Movahed et al., 2006; Telesca \& Toth, 2016; Zorick \& Mandelkern, 2013; Zunino et al., 2008).

The first four steps (i-iv) in MFDFA method are the same as for DFA (Kantelhardt et al., 2002).

The average value of local variance (2) is calculated on all windows to obtain the fluctuation function of order $q$

$$
F_{q}(n)=\left\{\frac{1}{N_{n}} \sum_{w=1}^{N_{n}}\left[F^{2}(n, s]^{\frac{q}{2}}\right\}^{\frac{1}{q}}\right.
$$

where, $q$ can be any real value, except zero. For $q=0, F_{q}(n)$ is calculated as $\left[F_{\varepsilon}(n)+F_{-\varepsilon}(n)\right] / 2$, where $\varepsilon \rightarrow 0$. This calculation is repeated for different segment sizes, providing the relationship between the fluctuation function $F_{q}(n)$ and the size of the segment $n$. If the series $x_{i}$ has the long-range correlations, the fluctuation function $F_{q}(n)$ increases with $n$, as a power law,

$$
F_{q}(n) \sim n^{h(q)}
$$

The scaling exponent $h(q)$ is obtained as the slope of the linear regression of $\log F_{q}(n)$ versus $\log n$. The power law exponent $h(q)$ is called the generalized Hurst exponent; for stationary time series, $h(2)$ is identical to the well-known Hurst exponent $H$, and MFDFA reduces on DFA. For multifractal series $h(q)$ is the decreasing function of $q$, while for monofractal time series $h(q)$ 
is independent of $q$.

For positive values of $q, h(q)$ describes the scale invariance of the segments with large fluctuations, for negative values of $q, h(q)$ describes the scale invariance of the segments with small fluctuations. Generalized Hurst exponents $h(q)$ are related to the Renyi exponents $\tau(q)$ defined as $\tau(q)=q h(q)-1$. For monofractal series $\tau(q)$ is a linear function of $q$, and for multifractal series $\tau(q)$ is a nonlinear function of $q$. A multifractal process can also be characterized by the singularity spectrum $f(\alpha)$ which is related to $\tau(q)$ through the Legendre transform:

$$
\begin{gathered}
\alpha(q)=\frac{d \tau(q)}{d q}, \\
f(\alpha(q))=q \alpha(q)-\tau(q),
\end{gathered}
$$

where $f(\alpha)$ is the fractal dimension of the support of singularities in the measure with Lipschitz-Holder exponent $\alpha$. The singularity spectrum of monofractal series is represented by a single point in the $f(\alpha)$ plane, whereas the multifractal series yields a single humped function (Movahed et al., 2006).

A set of parameters can be extracted from the multifractal spectra for the characterization of process complexity (Shimizu et al., 2002; Stošić et al., 2015). The singularity spectra are fitted to a fourth-degree polynomial:

$$
f(\alpha)=A+B\left(\alpha-\alpha_{0}\right)+C\left(\alpha-\alpha_{0}\right)^{2}+D\left(\alpha-\alpha_{0}\right)^{3}+E\left(\alpha-\alpha_{0}\right)^{4}
$$

and the multifractal spectrum parameters are found as the position of maximum $\alpha_{0}$, width of the spectrum $W=\alpha_{\max }-\alpha_{\min }$, obtained from extrapolating the fitted curve to zero, and the skew parameter $\left.r=\left(\alpha_{\max }-\alpha_{0}\right) / \alpha_{0}-\alpha_{\min }\right)$ where $r=1$ for symmetric shapes, $r>1$ for right-skewed shapes, and $r<1$ for left-skewed shapes.

The parameter $\alpha_{0}$ is the position of the maximum of $f(\alpha)$, and provides an estimate of the overall Hurst exponent in which, a value of $\alpha_{0}>0,5$ indicates a correlated or persistent process, $\alpha_{0}<0,5$ an anti-correlated or anti-persistent process and $\alpha_{0}=0,5$ indicates a totally random process. The parameter $W$ is the width of the spectrum, and measures the amplitude of fractal exponents required to describe the signal. The larger the width of the spectrum means the stronger multifractality of the process.

The asymmetry parameter $r$, which can be calculated as serves to measure the dominance of small and large fluctuations in the multifractal spectrum. If $r=1$, the spectrum is symmetrical and both large and small fluctuations contribute equally to multifractality, $r>1$ means that the spectrum is asymmetrical to the right, indicating that subsets with small fluctuations have a greater contribution to the multifractal spectrum and $r<1$ means that the spectrum has a left asymmetry, indicating that subsets with large fluctuations have a greater contribution to the multifractal spectrum (Shimizu et al., 2002; Stošić et al., 2015).

We analyzed long daily rainfall record collected in meteorological station in Recife during the period 1962-2019. We applied DFA method on magnitude and sign series which carry information about the nonlinear and linear properties of the series respectively. We applied MFDFA on deseasonalided series and calculated multifractal parameters (that quantify position of maximum, width and asymmetry of multifractal spectrum). We compared the values of these parameters related to different properties of rainfall fluctuations, for two 29 years sub periods.

\section{Results and Discussion}

We analyze deseasonalized series (anomalies) of daily rainfall $x(t)$

$$
X(t)=\frac{x(t)-\mu_{t}}{\sigma_{t}}
$$

where $\mu_{t}$ is the mean daily rainfall calculated for each calendar date by averaging over all years in the record, and $\sigma_{t}$ is the standard deviation of $x(t)$, also calculated for each calendar date [8]. We apply DFA method on daily anomaly series and two derived series: magnitude $M(t)=|\Delta X(t)|$ and $\operatorname{sign} S(t)=\operatorname{sign}[\Delta X(t)]$. The magnitude series carries information about 
the nonlinear properties of the series, while the sign series relates importantly to linear properties (Jha \& Sivakumar, 2017b).

Original, anomalies, magnitude and sign series are shown on Figure 1.

Figure 1. Daily series of (a) original rainfall data, (b) anomalies, (c) magnitude and (d) sign for Recife station.
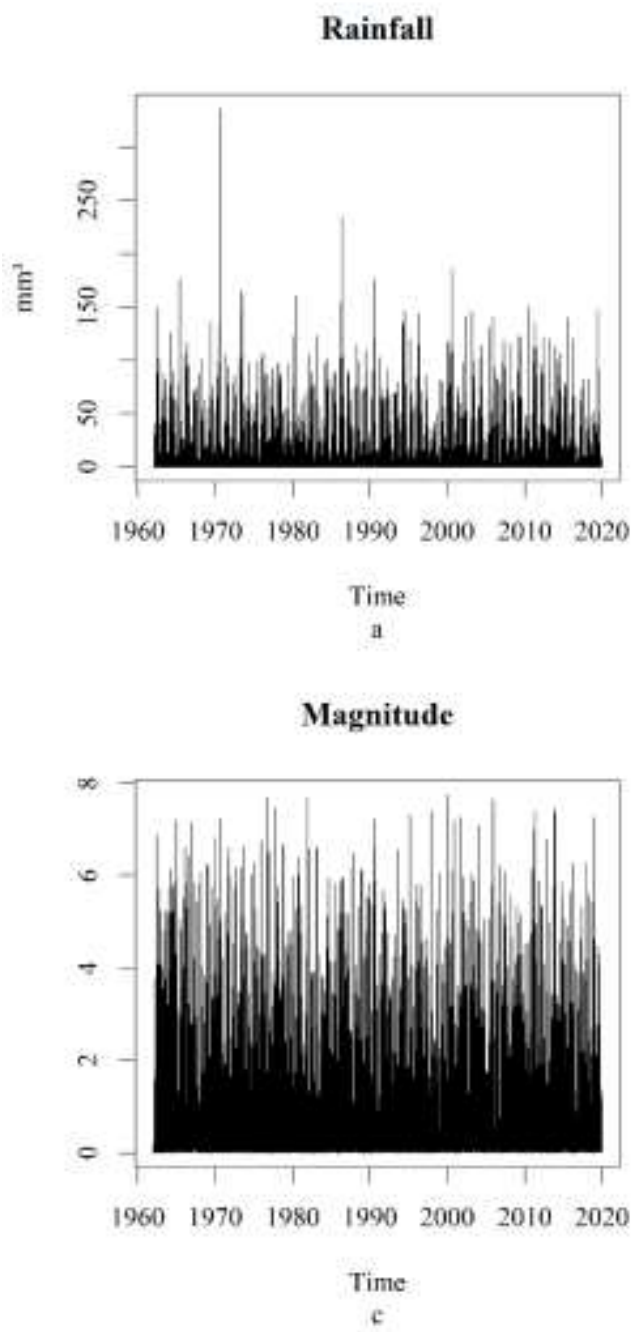
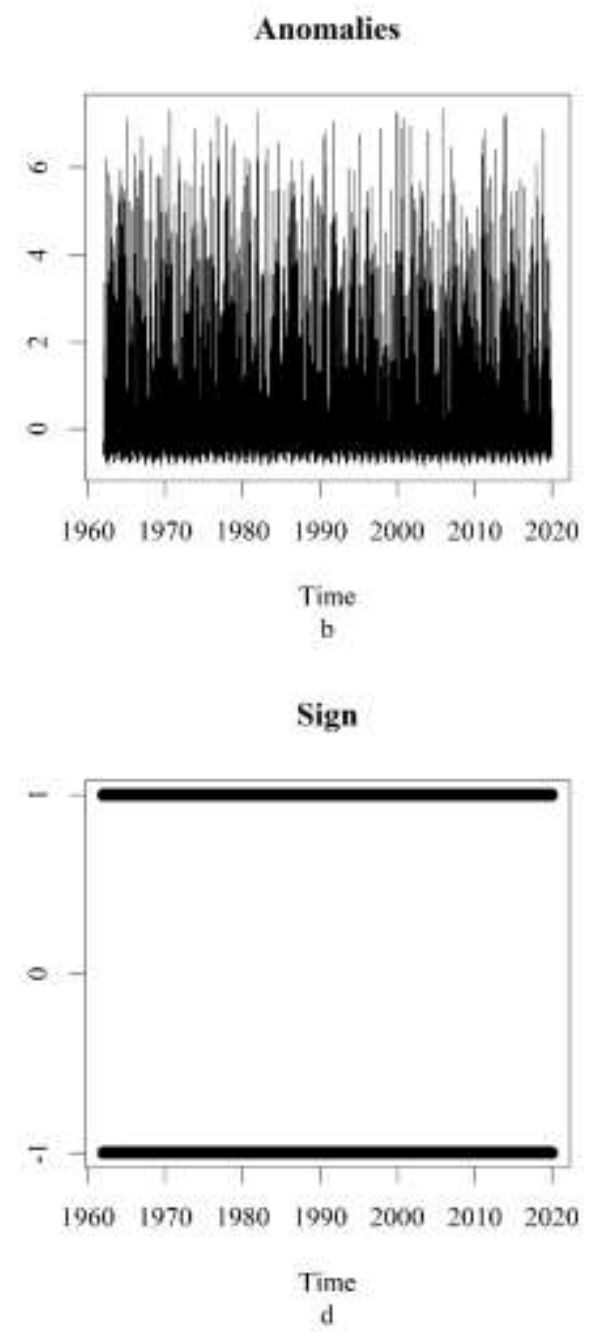

Source: Authors.

We apply DFA analysis on entire series (1962-2019) and on two sub periods:1962-1990 and 1991-2019 in order to identify possible climatic changes. The DFA graphs for anomalies, magnitude and sign for entire series are shown in Figure 2 and for two sub series in Figure 3, where clear linear relationship between fluctuation function and window size on log-log scale is observed, indicating the existence of long-term correlations. 
Research, Society and Development, v. 10, n. 2, e15410212424, 2021

(CC BY 4.0) | ISSN 2525-3409 | DOI: http://dx.doi.org/10.33448/rsd-v10i2.12424

Figure 2. DFA graphs for (a)anomalies, (b)magnitude and (c) sign series for daily rainfall data at Recife.
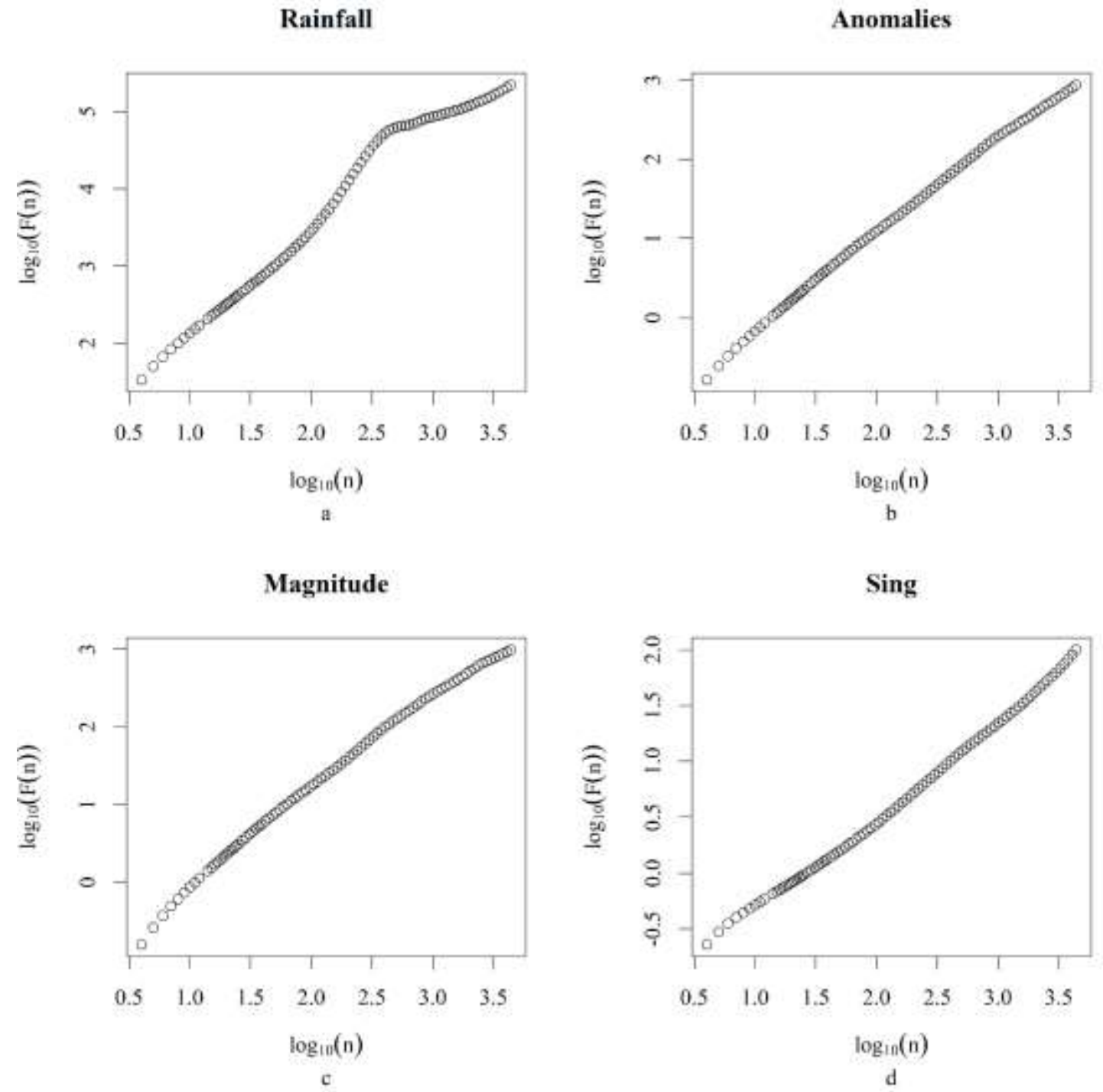

Source: Authors. 
Figure 3. DFA graphs for (a) anomalies, (b) magnitude and (c) sign series for daily rainfall data for Recife for two subperiods: 1962-1990 and 1991-2019.
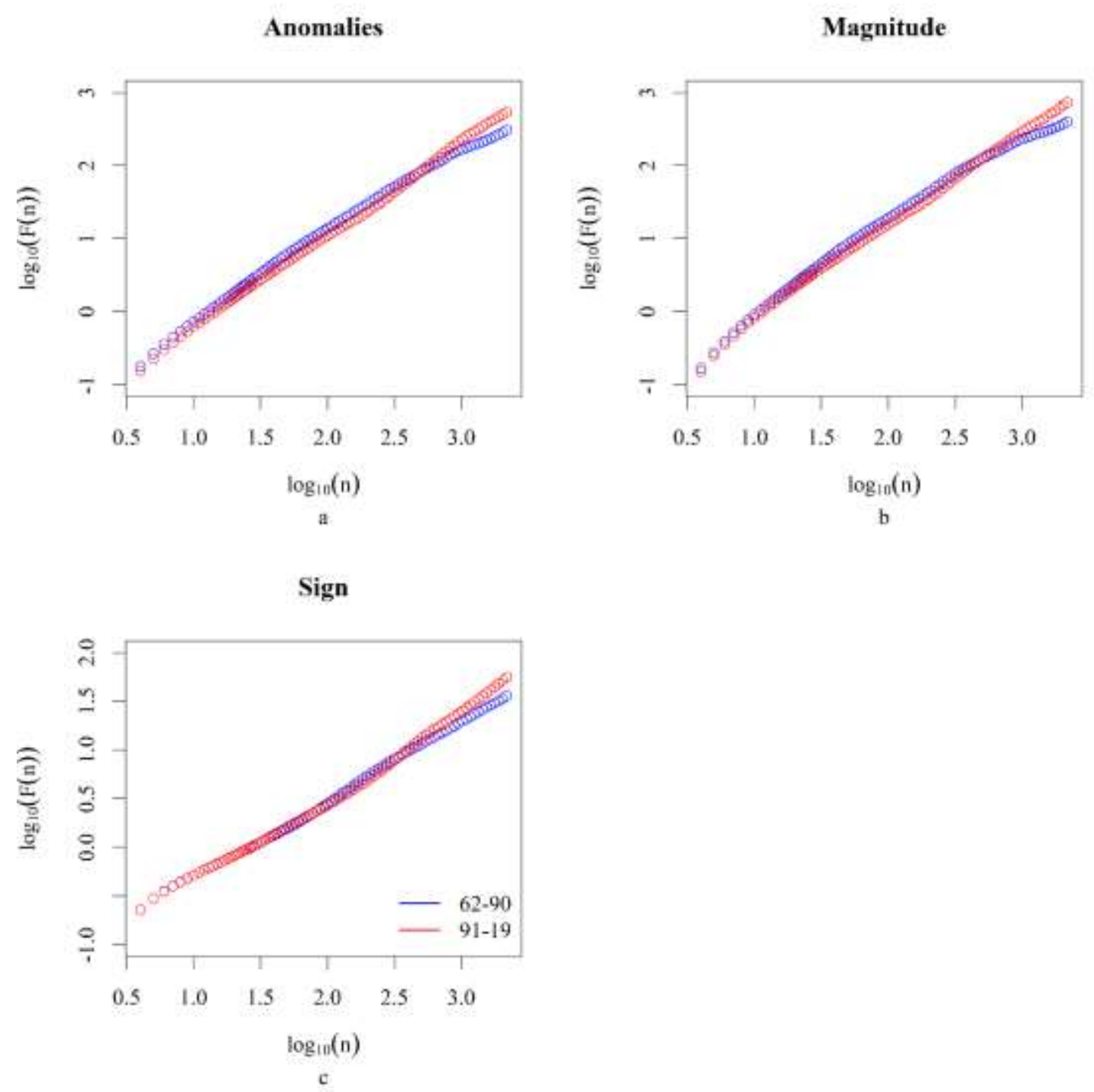

Source: Authors.

The values of DFA exponents (calculated as slope of the linear regression of $\log F(n)$ versus $\log n$ ) are shown on Table 1, where it is seen that anomalies and magnitude series show persistent long-term correlations $(\alpha>0.5)$, while sign series are anti persistent $(\alpha<0.5)$. Persistence in the magnitude series indicates that an increment with large (small) magnitude is more likely to be followed by an increment with large (small) magnitude.

Anticorrelation in the sign series indicates that a positive (negative) increment is more likely to be followed by a negative (positive) increment. For entire series and for two sub periods, the values of DFA exponents are very close and don't reveal relation with climatic changes. The persistence of magnitude series indicates that the original series (in our case rainfall anomalies) has multifractal properties (Jha \& Sivakumar, 2017b).

The persistence in magnitude series and anti-persistence in sign series indicate that a large increment in the positive direction is more likely to be followed by a large increment in the negative direction, and this holds over a broad range of time scales from several days to three years. 
Table 1. DFA exponent values for anomalies, magnitude and sign series for daily rainfall data for Recife station.

\begin{tabular}{lccc}
\hline Period & Anomalies & Magnitude & Sign \\
\hline $1962-2019$ & 0,614 & 0,631 & 0,391 \\
$1962-1990$ & 0,628 & 0,646 & 0,387 \\
$1991-2019$ & 0,610 & 0,622 & 0,372 \\
\hline
\end{tabular}

Source: Authors.

The results of multifractal analysis (with MFDFA method) for two sub periods are shown in Figure 5 and Figure 6 respectively, where it is seen that all graphs, fluctuation functions $F_{q}(n)$, generalized Hurst exponent $h(q)$, Rényi exponent $\tau(q)$ and multifractal spectrum $f(\alpha)$, show that rainfall anomalies series are generated by multifractal process: $F_{q}(n)$ is linear function on logaritmic scale, $h(q)$ is decreasing function, $\tau(q)$ is nonlinear function $\mathrm{m}$ and $f(\alpha)$ is a single humped function (Movahed et al., 2006).

The values of multifractal spectrum parameters, the position of maximum $\alpha_{0}$, width $W$ and asymmetry parameter $r$ are shown on Table 2 where we observe changes in rainfall regime towards stronger persistency (higher $\alpha_{0}$ ) weaker multifractality (lower $W$ ) and the equal dominance of both small and large fluctuations $(r \sim 1)$.

Before 1990 multifractality of rainfall anomalies was mostly caused by the scaling behavior of small fluctuations $(r>$ 1), indicating that extreme events that produce large fluctuation with respect to linear trend become more frequent, leading to the loss of right asymmetry of multifractal spectrum.

Oliveira et al. (2017) performed trend analysis of occurrence and intensity of extreme events of precipitation in subregions of Northeast Brazil (NEB). They analyzed daily rainfall data of 148 rain gauges recorded during the period from 1972 to 2002 and used quantiles technique to define weak, normal and heavy rainfall events. They found that in coastal region the rainy period is characterized by more intense and more frequent rainfall, while the dry period is characterized by less intense and less frequent rains (Oliveira et al., 2017). 
Figure 5. Multifractal analysis of daily rainfall anomalies between 1962 and 1990, at Recife station: (a) fluctuation functions $F_{q}(n)$ versus box size $(n)$; (b) generalized Hurst exponent $h(q)$; (c) Rényi exponent $\tau(q)$; (d) Multifractal spectrum $f(\alpha)$ together with fourth degree polynomial fit (red line).
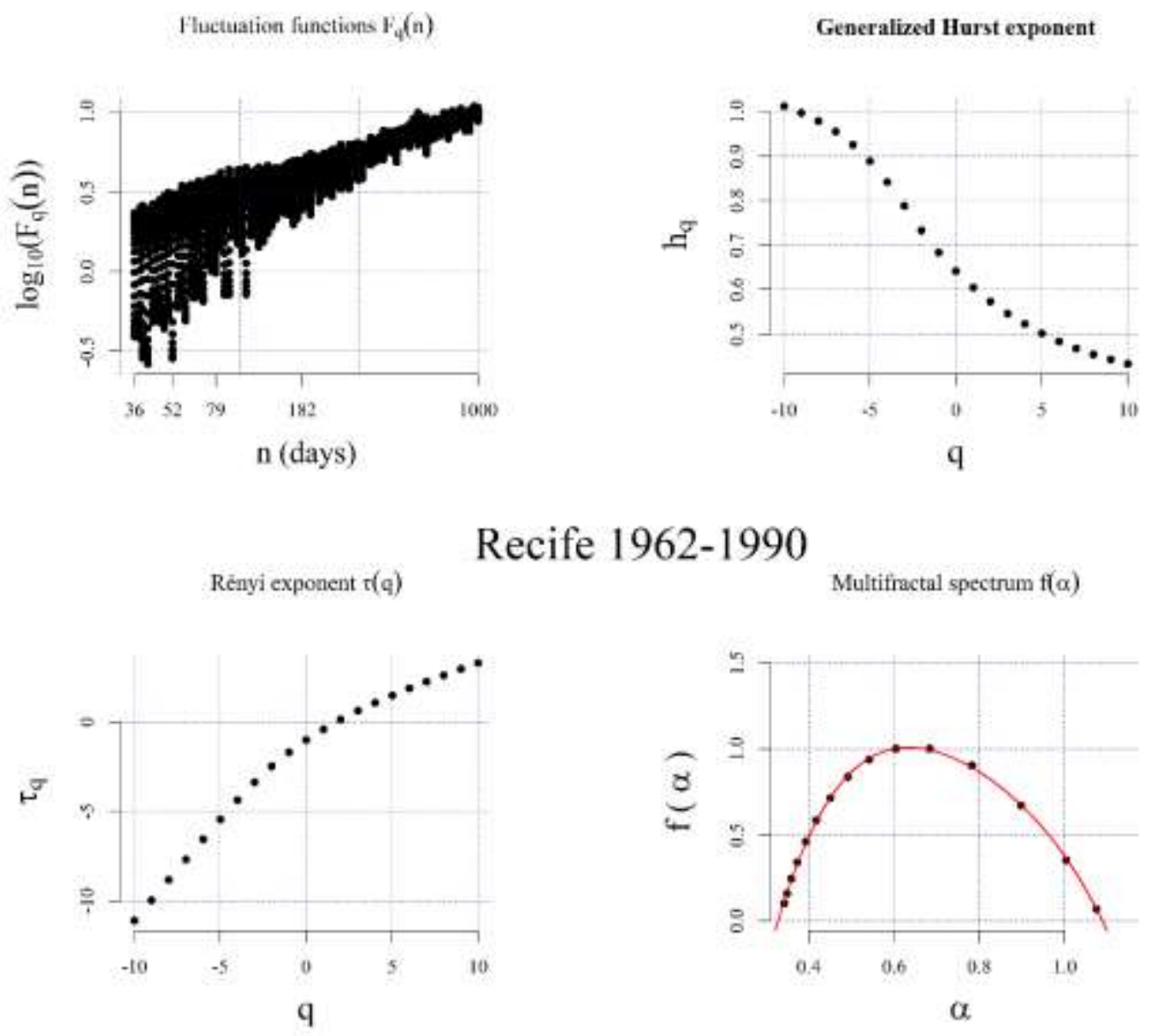

Recife 1962-1990

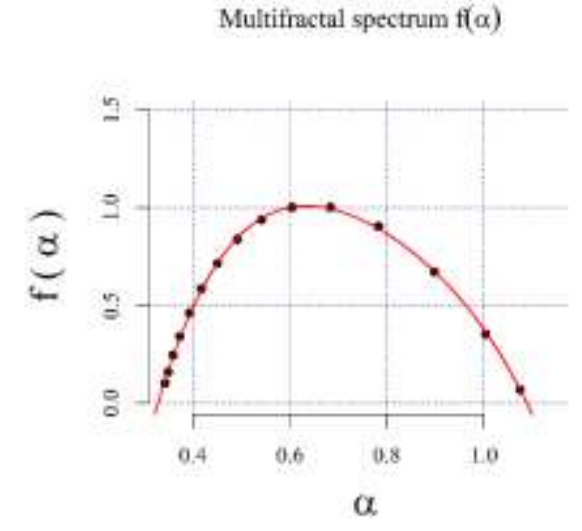

Source: Authors.

The changes in values of the multifractal parameters after 1990 are in agreement with these results: the decrease of dominance of small fluctuations in multifractality of rainfall anomalies, which also exhibits stronger persistence indicating more regular dynamics. Krzyszczak et al. (2019) performed multifractal analysis (using MFDFA) for meteorological time series recorded in stations located in varying climatic zones in Poland and Bulgaria.

They compared multifractal spectra between the two sub-periods, namely 1980-2001 and 2002-2010 and found that for precipitation data from some stations the values of $\alpha_{0}$ change only slightly and are greater in the second sub-period, while the width of multifractal spectrum decreases. 
Figure 6. Multifractal analysis of daily rainfall anomalies between 1991 and 2019, at Recife station: (a) fluctuation functions $F_{q}(n)$ versus box size $(n)$; (b) generalized Hurst exponent $h(q)$; (c) Rényi exponent $\tau(q)$; (d) Multifractal spectrum $f(\alpha)$ together with fourth degree polynomial fit (red line).
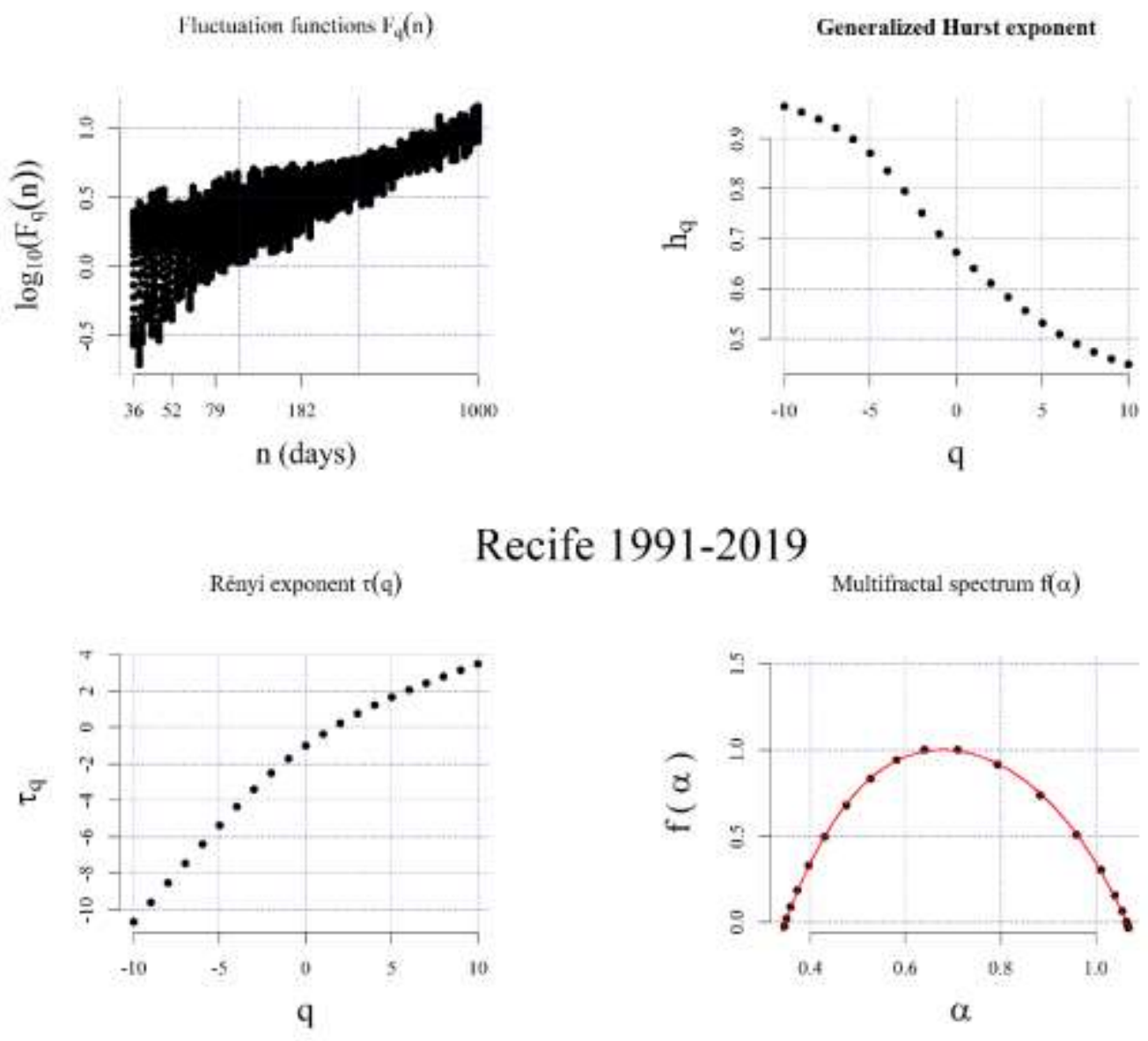

Source: Authors.

Most consistent changes were observed in the case of the asymmetry, for all stations this parameter is generally lower, the spectrum tends to be more symmetrical or the asymmetry changes from right to left-skewed which means that more extreme events can be observed for this sub-period. Although the climate at the location of Recife is very different that in Poland and Bulgaria, the changes in multifractal spectrum after 1990 indicate similar shift in rainfall regime: stronger persistency, weaker multifractality and lower asymmetry, indicating that after 1990 more extreme events are present in the rainfall time series.

Table 2. Complexity parameters $\alpha_{0}, \mathrm{~W}$ and $\mathrm{r}$ of the multifractal spectrum $f(\alpha)$ of the daily rainfall anomalies two sub periods: 1962-1990 and 1991-2019.

\begin{tabular}{lccc}
\hline Period & $\alpha_{0}$ & W & r \\
\hline $1962-1990$ & 0,683 & 0,806 & 1,362 \\
$1991-2019$ & 0,709 & 0,724 & 0,986 \\
\hline
\end{tabular}




\section{Final Considerations}

In this work we investigated the change of rainfall regime in coastal region of Pernambuco, Brazil by using multifractal analysis. We analyzed daily rainfall temporal series recorded at Recife station during the period 1962 - 2019. By applying the well-established method of Multifractal Detrended Fluctuation Analysis (MFDFA), we calculated multifractal spectrum and determined its complexity parameters (position of maximum, width and asymmetry) that are related to different properties of rainfall fluctuations.

The changes in the values of multifractal parameters for two 29 years sub periods indicated following changes in rainfall dynamics: i) stronger persistency (position of maximum of multifractal spectrum shifts towards higher value); weaker multifractality (width of the spectrum decreases) and increased dominance of larges fluctuation (the spectrum loses asymmetry to the right). These results showed that multifractal spectra were sensitive to climatic shift, as indicated by the changes of spectra parameters.

Future studies should involve larger number of meteorological series, particularly long-term rainfall and temperature data in order to investigate if multifractal analysis (along classical statistical methods) can be useful to detect some aspects of climate changes.

\section{References}

Adarsh, S., Nourani, V., Archana, D. S., \& Dharan, D. S. (2020). Multifractal description of daily rainfall fields over India. Journal of Hydrology, 586, 124913. https://doi.org/10.1016/j.jhydrol.2020.124913

Arvor, D., Dubreuil, V., Ronchail, J., Simões, M., \& Funatsu, B. M. (2014). Spatial patterns of rainfall regimes related to levels of double cropping agriculture systems in Mato Grosso (Brazil). International Journal of Climatology, 34(8), 2622-2633. https://doi.org/10.1002/joc.3863

da Silva, H. S., Silva, J. R. S., \& Stosic, T. (2020). Multifractal analysis of air temperature in Brazil. Physica A: Statistical Mechanics and Its Applications, 549, 124333. https://doi.org/10.1016/j.physa.2020.124333

De Benicio, R. B., Stošić, T., De Figueirêdo, P. H., \& Stošić, B. D. (2013). Multifractal behavior of wild-land and forest fire time series in Brazil. Physica A: Statistical Mechanics and Its Applications, 392(24), 6367-6374. https://doi.org/10.1016/j.physa.2013.08.012

Douglas, E. M., \& Barros, A. P. (2003a). Probable maximum precipitation estimation using multifractals: Application in the eastern United States. Journal of Hydrometeorology, 4(6), 1012-1024. https://doi.org/10.1175/1525-7541(2003)004<1012:PMPEUM>2.0.CO;2

Douglas, E. M., \& Barros, A. P. (2003b). Probable maximum precipitation estimation using multifractals: Application in the eastern United States. Journal of Hydrometeorology, 4(6), 1012-1024. https://doi.org/10.1175/1525-7541(2003)004<1012:PMPEUM>2.0.CO;2

Fuwape, I. A., Ogunjo, S. T., Oluyamo, S. S., \& Rabiu, A. B. (2017). Spatial variation of deterministic chaos in mean daily temperature and rainfall over Nigeria. Theoretical and Applied Climatology, 130(1-2), 119-132. https://doi.org/10.1007/s00704-016-1867-X

García-Marín, A. P., Estévez, J., Medina-Cobo, M. T., \& Ayuso-Muñoz, J. L. (2015). Delimiting homogeneous regions using the multifractal properties of validated rainfall data series. Journal of Hydrology, 529(P1), 106-119. https://doi.org/10.1016/j.jhydrol.2015.07.021

García-Marín, Amanda P., Jiménez-Hornero, F. J., \& Ayuso-Muñoz, J. L. (2008). Multifractal analysis as a tool for validating a rainfall model. Hydrological Processes, 22(14), 2672-2688. https://doi.org/10.1002/hyp.6864

Haines, A., Kovats, R. S., Campbell-Lendrum, D., \& Corvalan, C. (2006). Climate change and human health: Impacts, vulnerability and public health. Public Health, 120(7), 585-596. https://doi.org/10.1016/j.puhe.2006.01.002

Herr, H. D., \& Krzysztofowicz, R. (2005). Generic probability distribution of rainfall in space: The bivariate model. Journal of Hydrology, 306(1-4), 234-263. https://doi.org/10.1016/j.jhydrol.2004.09.011

Jha, S. K., \& Sivakumar, B. (2017a). Complex networks for rainfall modeling: Spatial connections, temporal scale, and network size. Journal of Hydrology, 554, 482-489. https://doi.org/10.1016/j.jhydrol.2017.09.030

Jha, S. K., \& Sivakumar, B. (2017b). Complex networks for rainfall modeling: Spatial connections, temporal scale, and network size. Journal of Hydrology, 554(9), 482-489. https://doi.org/10.1016/j.jhydrol.2017.09.030

Kabo-Bah, A. T., Diji, C. J., Nokoe, K., Mulugetta, Y., Obeng-Ofori, D., \& Akpoti, K. (2016). Multiyear rainfall and temperature trends in the Volta River basin and their potential impact on hydropower generation in Ghana. Climate, 4(4), 49. https://doi.org/10.3390/cli4040049

Kantelhardt, J. W., Zschiegner, S. A., Koscielny-Bunde, E., Havlin, S., Bunde, A., \& Stanley, H. E. (2002). Multifractal detrended fluctuation analysis of nonstationary time series. Physica A: Statistical Mechanics and Its Applications, 316(1-4), 87-114. https://doi.org/10.1016/S0378-4371(02)01383-3

Krzyszczak, J., Baranowski, P., Zubik, M., Kazandjiev, V., Georgieva, V., Sławiński, C., Siwek, K., Kozyra, J., \& Nieróbca, A. (2019). Multifractal 
characterization and comparison of meteorological time series from two climatic zones. Theoretical and Applied Climatology, 137(3-4), 1811-1824. https://doi.org/10.1007/s00704-018-2705-0

Langousis, A., Veneziano, D., Furcolo, P., \& Lepore, C. (2009). Multifractal rainfall extremes: Theoretical analysis and practical estimation. Chaos, Solitons and Fractals, 39(3), 1182-1194. https://doi.org/10.1016/j.chaos.2007.06.004

Movahed, M. S., Jafari, G. R., Ghasemi, F., Rahvar, S., \& Tabar, M. R. R. (2006). Multifractal detrended fluctuation analysis of sunspot time series. Journal of Statistical Mechanics: Theory and Experiment, 316(2), 87-114. https://doi.org/10.1088/1742-5468/2006/02/P02003

Oliveira, P. T., Santos e Silva, C. M., \& Lima, K. C. (2017). Climatology and trend analysis of extreme precipitation in subregions of Northeast Brazil. Theoretical and Applied Climatology, 130(1-2), 77-90. https://doi.org/10.1007/s00704-016-1865-z

Park, J., Kang, H., Lee, Y. S., \& Kim, M. (2011). Changes in the extreme daily rainfall in South Korea. International Journal of Climatology, 31(15), 22902299

Park, J. S., Kang, H. S., Lee, Y. S., \& Kim, M. K. (2011). Changes in the extreme daily rainfall in South Korea. International Journal of Climatology, 31(15), 2290-2299. https://doi.org/10.1002/joc.2236

Peng, C. K., Buldyrev, S. V., Havlin, S., Simons, M., Stanley, H. E., \& Goldberger, A. L. (1994). Mosaic organization of DNA nucleotides. Physical Review E, 49(2), 1685-1689. https://doi.org/10.1103/PhysRevE.49.1685

Sa'adi, Z., Shahid, S., Ismail, T., Chung, E. S., \& Wang, X. J. (2019). Trends analysis of rainfall and rainfall extremes in Sarawak, Malaysia using modified Mann-Kendall test. Meteorology and Atmospheric Physics, 131(3), 263-277. https://doi.org/10.1007/s00703-017-0564-3

Shimizu, Y. U., Thurner, S., \& Ehrenberger, K. (2002). Multifractal spectra as a measure of complexity in human posture. Fractals, $10(1), 103-116$. https://doi.org/10.1142/S0218348X02001130

Stošić, D., Stošić, D., Stošić, T., \& Stanley, H. E. (2015). Multifractal analysis of managed and independent float exchange rates. Physica A: Statistical Mechanics and Its Applications, 428, 13-18. https://doi.org/10.1016/j.physa.2015.02.055

Svensson, C., Olsson, J., \& Berndtsson, R. (1996). Multifractal properties of daily rainfall in two different climates. Water Resources Research, 32(8), 24632472. https://doi.org/10.1029/96WR01099

Tan, X., \& Gan, T. Y. (2017). Multifractality of Canadian precipitation and streamflow. International Journal of Climatology, 37, 1221-1236. https://doi.org/10.1002/joc.5078

Telesca, L., \& Toth, L. (2016). Multifractal detrended fluctuation analysis of Pannonian earthquake magnitude series. Physica A: Statistical Mechanics and Its Applications, 448, 21-29. https://doi.org/10.1016/j.physa.2015.12.095

Weltzin, J. F., Loik, M. E., Schwinning, S., Williams, D. G., Fay, P. A., Haddad, B. M., Harte, J., Huxman, T. E., Knapp, A. K., Lin, G., Pockman, W. T., Shaw, M. R., Small, E. E., Smith, M. D., Smith, S. D., Tissue, D. T., \& Zak, J. C. (2003). Assessing the Response of Terrestrial Ecosystems to Potential Changes in Precipitation. In BioScience (Vol. 53, Issue 10, pp. 941-952). American Institute of Biological Sciences. https://doi.org/10.1641/00063568(2003)053[0941:ATROTE]2.0.CO;2

Xavier, S. F. A., da Silva Jale, J., Stosic, T., dos Santos, C. A. C., \& Singh, V. P. (2019). An application of sample entropy to precipitation in Paraíba State, Brazil. Theoretical and Applied Climatology, 136(1-2), 429-440. https://doi.org/10.1007/s00704-018-2496-3

Zorick, T., \& Mandelkern, M. A. (2013). Multifractal Detrended Fluctuation Analysis of Human EEG: Preliminary Investigation and Comparison with the Wavelet Transform Modulus Maxima Technique. PLoS ONE, 8(7), e68360. https://doi.org/10.1371/journal.pone.0068360

Zunino, L., Tabak, B. M., Figliola, A., Pérez, D. G., Garavaglia, M., \& Rosso, O. A. (2008). A multifractal approach for stock market inefficiency. Physica A: Statistical Mechanics and Its Applications, 387(26), 6558-6566. https://doi.org/10.1016/j.physa.2008.08.028 